TITLE:

\title{
Surface structures of equimolar mixtures of imidazolium-based ionic liquids using high-resolution Rutherford backscattering spectroscopy
}

\section{$\operatorname{AUTHOR(S):~}$}

Nakajima, Kaoru; Oshima, Shinichi; Suzuki, Motofumi; Kimura, Kenji

\section{CITATION:}

Nakajima, Kaoru ... [et al]. Surface structures of equimolar mixtures of imidazolium-based ionic liquids using high-resolution Rutherford backscattering spectroscopy. Surface Science 2012, 606(21-22): 1693-1699

ISSUE DATE:

2012-11

URL:

http://hdl.handle.net/2433/160100

\section{RIGHT:}

(C) 2012 Elsevier B.V.; This is not the published version. Please cite only the published version.; この論文は出版社版でありません。引用の際に は出版社版をご確認ご利用ください。 


\title{
Surface Structures of equimolar mixtures of imidazolium-based ionic liquids using High-resolution Rutherford Backscattering Spectroscopy
}

\author{
Kaoru Nakajima, Shinichi Oshima, Motofumi Suzuki and Kenji Kimura* \\ Department of Micro Engineering, Kyoto University, Yoshida-honmachi, Sakyo, Kyoto \\ 606-8501, Japan
}

Surface structures of equimolar mixtures of imidazolium-based ionic liquids (ILs) having a

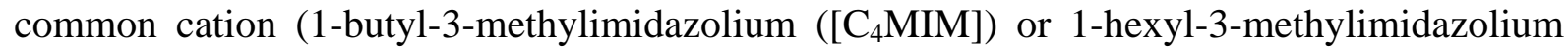
$\left(\left[\mathrm{C}_{6} \mathrm{MIM}\right]\right)$ and different anions (bis(trifluoromethanesulfonyl)imide ([TFSI]), hexafluorophosphate $\left(\left[\mathrm{PF}_{6}\right]\right)$ or chlorine) are studied using high-resolution Rutherford backscattering spectroscopy (HRBS). Both cations and anions have the same preferential orientations at the surface as in the pure ILs. In the mixture, the larger anion is located shallower than the smaller anion. The [TFSI] anion is slightly enriched at the surface relative to $\left[\mathrm{PF}_{6}\right]$ with coverage of $\sim 60 \%$ for the equimolar mixtures of $\left[\mathrm{C}_{4(6)} \mathrm{MIM}\right][\mathrm{TFSI}]$ and $\left[\mathrm{C}_{4(6)} \mathrm{MIM}\right]\left[\mathrm{PF}_{6}\right]$. No surface segregation is observed for $\left[\mathrm{C}_{6} \mathrm{MIM}\right][\mathrm{TFSI}]_{0.5}[\mathrm{Cl}]_{0.5}$ and $\left[\mathrm{C}_{6} \mathrm{MIM}\right]\left[\mathrm{PF}_{6}\right]_{0.5}[\mathrm{Cl}]_{0.5}$. These results are different from the recent TOF-SIMS measurement where very strong surface segregation of $[\mathrm{TFSI}]$ was concluded for the mixture of $\left[\mathrm{C}_{4} \mathrm{MIM}\right]$ [TFSI $]$ and $\left[\mathrm{C}_{4} \mathrm{MIM}\right]\left[\mathrm{PF}_{6}\right]$.

\footnotetext{
*Address correspondence to this author (E-mail: kimura@kues.kyoto-u.ac.jp)
} 


\section{Introduction}

Room-temperature ionic liquids (ILs) have many excellent properties, such as negligible vapor pressure, chemical stability, high heat capacity, high solvent power. This allows many promising applications, including clean solvents and catalysis for green chemistry [1 - 3], electrodeposition [4 - 6], lithium ion batteries [7, 8], capacitors [9, 10], fuel cells $[11,12]$, lubricants [13]. In these applications, not only bulk properties but also surface properties are often of prime importance. Because of their negligible vapor pressures a variety of surface analysis techniques, most of which require ultrahigh vacuum conditions, were used to study the surface structures of ILs. For example, direct recoil spectroscopy [14, 15], sum frequency generation (SFG) spectroscopy [16-19], X-ray reflectivity (XR) measurement [20], angle resolved X-ray photoelectron spectroscopy (ARXPS) [21-24], low energy ion scattering spectroscopy (LEIS) [25], metastable impact electron spectroscopy (MIES) [26], time of flight secondary ion mass spectroscopy (TOF-SIMS) [27, 28], high-resolution Rutherford backscattering spectroscopy (HRBS) [29-32] and Neutral impact collision ion scattering spectroscopy (NICISS) [33] have been applied. As a result of these extensive studies, a consensus has been established that both cations and anions are equally present in the surface region.

ILs are known as "designer solvents" because their properties can be tuned by appropriate combination of a wide range of anions and cations and also by mixing different ILs. There are, however, only few studies on the surface structure of the mixture of ILs. Recently, surface composition of binary mixtures of ILs was investigated using TOF-SIMS [28]. Although the charge neutrality holds at the surface, remarkable surface segregation of particular cation and/or anion was observed. For example, in a mixture of 1-octyl-3-methylimidazolium tetrafluoroborate $\quad\left(\left[\mathrm{C}_{8} \mathrm{MIM}\right] \quad\left[\mathrm{BF}_{4}\right]\right) \quad$ and 1-ethyl-3-methylimidazolium tetrafluoroborate $\left(\left[\mathrm{C}_{2} \mathrm{MIM}\right]\left[\mathrm{BF}_{4}\right]\right)$, the $\left[\mathrm{C}_{8} \mathrm{MIM}\right]$ cation is enriched at the surface. It was also found that bis(trifluoromethanesulfonyl)imide ([TFSI]) anions segregate to the surface in a mixture of $\left[\mathrm{C}_{4} \mathrm{MIM}\right][\mathrm{TFSI}]$ and $\left[\mathrm{C}_{4} \mathrm{MIM}\right]\left[\mathrm{PF}_{6}\right]$. The surface of an equimolar mixture of $\mathrm{Li}[\mathrm{TFSI}]$ and $\left[\mathrm{C}_{4} \mathrm{MIM}\right]\left[\mathrm{PF}_{6}\right]$ has a nominal composition of $\left[\mathrm{C}_{4} \mathrm{MIM}\right][\mathrm{TFSI}]$. These results indicate that larger cations and/or anions tend to 
segregate to the surface without breaking the charge balance at the surface. This suggests the possibility that the bulk and surface properties can be designed separately by mixing appropriate ILs. There are, however, a couple of reports conflicting with these TOF-SIMS results. Surface composition of a mixture of $\left[\mathrm{C}_{2} \mathrm{MIM}\right]$ [TFSI] and $\left[\mathrm{C}_{6} \mathrm{MIM}\right]$ [TFSI] was studied using HRBS and the result showed no surface enrichment of $\left[\mathrm{C}_{6} \mathrm{MIM}\right]$ [32]. A similar mixture of $\left[\mathrm{C}_{2} \mathrm{MIM}\right]$ [TFSI] and $\left[\mathrm{C}_{12} \mathrm{MIM}\right]$ [TFSI] was also studied using ARXPS and no surface enrichment of $\left[\mathrm{C}_{12} \mathrm{MIM}\right]$ was observed [24]. Thus the surface segregation of particular molecules in IL mixtures is still the subject of debate. In the present paper, the surface structures of equimolar binary mixtures of ILs, which have different anions and a common cation, were systematically studied using HRBS. The chosen substances are imidazolium based ILs, namely $\left[\mathrm{C}_{6} \mathrm{MIM}\right]$ [TFSI], [C $\left.{ }_{6} \mathrm{MIM}\right]\left[\mathrm{PF}_{6}\right],\left[\mathrm{C}_{6} \mathrm{MIM}\right] \mathrm{Cl},\left[\mathrm{C}_{4} \mathrm{MIM}\right]$ [TFSI $]$ and $\left[\mathrm{C}_{4} \mathrm{MIM}\right]\left[\mathrm{PF}_{6}\right]$.

\section{Experimental}

The details of the HRBS measurement were described elsewhere [34]. Briefly, $\mathrm{He}^{+}$ ions are produced by a Penning ion gauge type ion source and accelerated up to $400 \mathrm{keV}$ by a Cockcroft Walton type accelerator. The produced ion beam was mass analyzed by an analyzing magnet. The selected $\mathrm{He}^{+}$beam was collimated to $2 \times 2 \mathrm{~mm}^{2}$ by two sets of rectangular shaped slit system and sent to an ultra-high-vacuum (UHV) scattering chamber via a differential pumping system. The typical beam current was about $50 \mathrm{nA}$ and the base pressure of the UHV chamber was $1 \times 10^{-8} \mathrm{~Pa}$.

The ILs were purchased from Kanto Reagent (Japan) and measured by HRBS without further purification. In order to avoid possible radiation damage cause by the $\mathrm{He}^{+}$ ion irradiation, we developed a target system which is a similar device developed in the previous pioneering work [35]. A slowly rotating wheel (diameter $38 \mathrm{~mm}$ and rotation rate 1.5 - $6 \mathrm{rpm})$ was partially immersed in a reservoir $\left(7 \times 40 \times 15 \mathrm{~mm}^{3}\right)$ of IL so that the surface of the wheel was covered by a thin IL layer. The outermost part of the IL layer was removed by a skimmer (a razor blade) placed just above the reservoir to make a fresh and flat surface. Thus a thin fresh layer $(\sim 0.3 \mathrm{~mm})$ of IL having a clean and flat surface was prepared. This 
wheel system was mounted on a precision goniometer in the UHV scattering chamber. After loading the IL, the UHV chamber was evacuated by a turbo-molecular pump for more than one day. The HRBS spectra shown in this paper were measured after the chamber attained the vacuum in $10^{-6} \mathrm{~Pa}$.

The IL layer formed on the wheel surface was irradiated with the $400 \mathrm{keV} \mathrm{He}^{+}$beam. The He ions scattered from IL at a scattering angle $\theta \approx 50^{\circ}$ were energy analyzed by a $90^{\circ}$ sector type magnetic spectrometer and detected by a one-dimensional position sensitive detector (1D-PSD) of $100 \mathrm{~mm}$ length (the energy window was $25 \%$ of the central energy). The non-uniformity of the efficiency of the 1D-PSD was carefully calibrated so that a precise composition analysis can be performed.

\section{Results}

\subsection{Pure ILs}

Figure 1 shows an example of the HRBS spectrum observed at a scattering angle of $50.6^{\circ}$, when $400 \mathrm{keV} \mathrm{He}{ }^{+}$ions were incident on $\left[\mathrm{C}_{6} \mathrm{MIM}\right]\left[\mathrm{PF}_{6}\right]$ at an incident angle of $\theta_{\mathrm{i}}=$ 42.4 (exit angle was $\theta_{\mathrm{e}}=87^{\circ}$ ). There are several steps in the observed spectra. These steps correspond to the onset of the spectrum of each element. Knowing the stopping power, the energy scale can be converted to a depth scale as is shown in the upper abscissa for phosphorous. The solid line shows the result of the spectrum simulation for the IL having stoichiometric composition. The energy scale of the simulated spectrum is adjusted so that the leading edge of phosphorus agrees with the observed one. The agreement between the measurement and the simulation is roughly good, showing that the overall composition is close to the stoichiometric composition. Looking at the spectrum closely, however, a clear peak is seen at the leading edge of the carbon signal in the observed spectra but not in the simulated one. Other disagreements can be also seen around the leading edges of other elements. These disagreements suggest that the surface composition deviates from the stoichiometric composition. The energy spectrum was decomposed into the spectra of individual elements and the decomposed energy spectra were converted into depth profiles using the stopping power. The detailed procedure was described elsewhere [29]. 
Figure 2 shows the derived composition depth profiles. The horizontal dashed lines show the stoichiometric composition. Although the measured profiles roughly agree with the stoichiometric composition at deeper depths, the surface composition deviates from the stoichiometric one. The carbon profile has a peak at a depth $d \sim 0.3 \mathrm{~nm}$, while deficiency of other elements is seen in the surface region at $d<0.4 \mathrm{~nm}$, suggesting that the $\left[\mathrm{PF}_{6}\right]$ anion and the imidazolium ring are located slightly deeper region than the alkyl chain of the cations. The leading-edge positions of elements, which are shown by arrows in Fig. 2, are plotted in Fig. 3 ( $\mathbf{m}$ ). The nitrogen leading edge is located about $0.25 \mathrm{~nm}$ deeper than carbon, indicating that the alkyl chain of the $\left[\mathrm{C}_{6} \mathrm{MIM}\right]$ cation protrudes to the vacuum. Concerning the position of the $\left[\mathrm{PF}_{6}\right]$ anion, the leading edges of fluorine and phosphorus are located at almost the same depth of the nitrogen leading edge. This means that the $\left[\mathrm{PF}_{6}\right]$ anion is located at almost the same depth of the imidazolium ring of the $\left[\mathrm{C}_{6} \mathrm{MIM}\right]$ cation. Considering the fact that the positive charge of the $\left[\mathrm{C}_{6} \mathrm{MIM}\right]$ cation is localized in the imidazolium ring, this configuration seems reasonable because no electric dipole layer is induced.

Other ionic liquids were also analyzed in the same way. Figure 3 also shows the results of $\left[\mathrm{C}_{6} \mathrm{MIM}\right][\mathrm{TFSI}](\bullet),\left[\mathrm{C}_{6} \mathrm{MIM}\right] \mathrm{Cl}(\boldsymbol{\Delta}),\left[\mathrm{C}_{4} \mathrm{MIM}\right]\left[\mathrm{PF}_{6}\right](\square)$ and $\left[\mathrm{C}_{4} \mathrm{MIM}\right][\mathrm{TFSI}]$ (०). These results indicate that the position of the nitrogen leading edge is deeper than that of carbon. This means that the protrusion of the alkyl chain to the vacuum is a universal feature for $\left[\mathrm{C}_{\mathrm{n}} \mathrm{MIM}\right]$ cations irrespective of anion in accordance with the previous observations [16-19, 21-24, 31, 32].

For $\left[\mathrm{C}_{6} \mathrm{MIM}\right][\mathrm{TFSI}]$ and $\left[\mathrm{C}_{4} \mathrm{MIM}\right][\mathrm{TFSI}]$, the leading edges of sulfur and oxygen are located at almost the same depth of the nitrogen edge and the fluorine edge is located at slightly shallower depth than those of the sulfur and oxygen. This indicates that the [TFSI] anion has a preferential orientation at the surface, namely the $\mathrm{CF}_{3}$ groups of the [TFSI] anions are pointing toward the vacuum and the $\mathrm{N}\left(\mathrm{SO}_{2}\right)_{2}$ moiety is located nearly at the same depth as the imidazolium ring in accordance with our previous study [32]. The $\mathrm{Cl}$ anion is also located at almost the same depth as the imidazolium ring for $\left[\mathrm{C}_{6} \mathrm{MIM}\right] \mathrm{Cl}(\boldsymbol{\Delta})$. Summarizing the results of the pure ILs, the alkyl chains of the $\left[\mathrm{C}_{\mathrm{n}} \mathrm{MIM}\right]$ cations protrude to 
the vacuum. The anions are located at almost the same depth of the imidazolium ring. The observed surface structures are very similar to the characteristic structures of bulk ionic liquids where microscopic phase separation among neutral domains of alkyl chains and charged domains of imidazolium rings and anions takes place. The nonpolar alkyl chains protruding toward the vacuum effectively screen the electric field induced by the charged domains located in the deeper region. This reduces the surface energy and stabilizes the surface.

\subsection{Equimolar mixture of $\left[\mathrm{C}_{6} \mathrm{MIM}\right][\mathrm{TFSI}]$ and $\left[\mathrm{C}_{6} \mathrm{MIM}\right]\left[\mathrm{PF}_{6}\right]$}

Figure 4 shows HRBS spectrum of equimolar mixture of [ $\left.\mathrm{C}_{6} \mathrm{MIM}\right]$ [TFSI] and $\left[\mathrm{C}_{6} \mathrm{MIM}\right]\left[\mathrm{PF}_{6}\right]$. For comparison, the simulated spectrum for stoichiometric composition is also shown by a solid line. The agreement between the observed and simulated results is roughly good but there are discrepancies near the leading edges of fluorine, oxygen and carbon, suggesting that the surface composition deviates from the bulk composition. For detailed analysis, the elemental depth profiles were derived from the HRBS spectrum. In this derivation, separation of the sulfur signal from the phosphorus signal is not straightforward because these signals almost completely overlaps due to their small mass difference. We assumed that the depth profile of sulfur is equal to the oxygen profile divided by two because both oxygen and sulfur are only present in the $\mathrm{SO}_{2}$ moieties of the [TFSI] anions.

Figure 5(a) shows the derived composition depth profiles. The dashed lines show the stoichiometric composition. Although the measured profiles roughly agree with the stoichiometric composition at deeper depths, the surface composition deviates from the stoichiometric one. Both sulfur and oxygen are enriched at the surface while phosphorous is deficient. This indicates that the $[\mathrm{TFSI}]$ anion is dominant over the $\left[\mathrm{PF}_{6}\right]$ anion at the surface. For quantitative estimation, the average composition of the surface layer of $0.8 \mathrm{~nm}$ thickness (corresponding to the topmost molecular layer) was calculated by integrating the composition profiles. The obtained composition is shown in Table 1, where the stoichiometric composition is also shown in parentheses for comparison. A large 
phosphorous deficiency (-60\%) and notable enrichment of sulfur and oxygen $(+20 \%)$ are clearly seen, indicating that the surface composition is different from the bulk composition. Assuming that the charge balance is fulfilled at the surface, the surface composition can be expressed by $\left[\mathrm{C}_{6} \mathrm{MIM}\right][\mathrm{TFSI}]_{\mathrm{x}}\left[\mathrm{PF}_{6}\right]_{1-\mathrm{x}}$. From the observed phosphorous deficiency, $\mathrm{x}$ is estimated to be $0.8 \pm 0.1$ while $\mathrm{x}=0.60 \pm 0.03$ is obtained from the observed enrichment of sulfur and oxygen. The discrepancy between these two numbers can be resolved by considering the surface structure in detail (see below). Note that there is also a small fluorine deficiency $(\sim 13 \%)$. This can be also explained by considering the detailed surface structure.

Figure $6(\mathrm{a})$ shows the leading-edge positions of the elements for $\left[\mathrm{C}_{6} \mathrm{MIM}\right][\mathrm{TFSI}]_{0.5}$ $\left[\mathrm{PF}_{6}\right]_{0.5}$. The leading edge of nitrogen is about $0.2 \mathrm{~nm}$ deeper than that of carbon, indicating that the alkyl chain of the $\left[\mathrm{C}_{6} \mathrm{MIM}\right]$ cation protrudes to the vacuum as is the case of pure ILs. Concerning the [TFSI] anion, the leading edges of sulfur and oxygen are located at shallower depths than nitrogen by $\sim 0.03 \mathrm{~nm}$ and the fluorine edge is located at a shallower depth than those of the sulfur and oxygen by $\sim 0.1 \mathrm{~nm}$. This indicates that the $\mathrm{CF}_{3}$ groups of the [TFSI] anions are pointing toward the vacuum and the $\mathrm{N}\left(\mathrm{SO}_{2}\right)_{2}$ moiety is located shallower than the imidazolium ring by $\sim 0.03 \mathrm{~nm}$, i.e. the $[\mathrm{TFSI}]$ anions have the same molecular orientation as pure $\left[\mathrm{C}_{6} \mathrm{MIM}\right][\mathrm{TFSI}]$ but they are located slightly shallower with respect to the imidazolium ring. On the other hand, phosphorous edge is located deeper than the nitrogen edge by $\sim 0.2$ $\mathrm{nm}$, indicating that $\left[\mathrm{PF}_{6}\right]$ anions are located deeper than the imidazolium ring. Figure $7(\mathrm{a})$ shows the schematic drawing of the surface structure of $\left[\mathrm{C}_{6} \mathrm{MIM}\right][\mathrm{TFSI}]_{0.5}\left[\mathrm{PF}_{6}\right]_{0.5}$ determined here.

The above mentioned discrepancy between $\mathrm{x}=0.8 \pm 0.1$ (estimated from the surface deficiency of phosphorous) and $x=0.6 \pm 0.1$ (estimated from the surface enrichment of sulfur and oxygen) can be resolved by the surface structure (Fig. 7(a)). These numbers were derived from the average composition of the surface layer of $0.8 \mathrm{~nm}$ thickness. Because $\left[\mathrm{PF}_{6}\right]$ anions are located at slightly deeper positions, some phosphorus atoms are located deeper than $0.8 \mathrm{~nm}$. This means that the phosphorous concentration shown in Table 1 is smaller than the actual phosphorous concentration of the topmost molecular layer. This 
results in overestimate of $\mathrm{x}$. On the other hand, [TFSI] anions are located slightly shallower region and are within the surface layer of $0.8 \mathrm{~nm}$ thickness. Thus the result $\mathrm{x}=0.6 \pm 0.1$ which was determined using the observed surface enrichment of oxygen and sulfur is more reliable than the other one. A small fluorine deficiency (13\% deficiency) in the surface layer of $0.8 \mathrm{~nm}$ thickness is also attributed to the fact that some fluorine atoms in $\left[\mathrm{PF}_{6}\right]$ anions are located deeper than $0.8 \mathrm{~nm}$.

Summarizing the surface structure of equimolar mixture of $\left[\mathrm{C}_{6} \mathrm{MIM}\right][\mathrm{TFSI}]$ and $\left[\mathrm{C}_{6} \mathrm{MIM}\right]\left[\mathrm{PF}_{6}\right]$, the molecular composition of the topmost molecular layer is $\left[\mathrm{C}_{6} \mathrm{MIM}\right]$ $[\mathrm{TFSI}]_{0.6}\left[\mathrm{PF}_{6}\right]_{0.4}$. The alkyl chain of the $\left[\mathrm{C}_{6} \mathrm{MIM}\right]$ cation protrudes to the vacuum. The $\mathrm{CF}_{3}$ groups of the [TFSI] anions are pointing toward the vacuum and the $\mathrm{N}\left(\mathrm{SO}_{2}\right)_{2}$ moiety is located shallower than the imidazolium ring. On the other hand, the $\left[\mathrm{PF}_{6}\right]$ anions are located deeper than the imidazolium ring.

\subsection{Equimolar mixture of $\left[\mathrm{C}_{4} \mathrm{MIM}\right][\mathrm{TFSI}]$ and $\left[\mathrm{C}_{4} \mathrm{MIM}\right]\left[\mathrm{PF}_{6}\right]$}

A similar analysis was performed for the equimolar mixture of $\left[\mathrm{C}_{4} \mathrm{MIM}\right][\mathrm{TFSI}]$ and $\left[\mathrm{C}_{4} \mathrm{MIM}\right]\left[\mathrm{PF}_{6}\right]$. Figures $5(\mathrm{~b})$ shows the derived composition depth profiles. Similarly to the case of the equimolar mixture of $\left[\mathrm{C}_{6} \mathrm{MIM}\right][\mathrm{TFSI}]$ and $\left[\mathrm{C}_{6} \mathrm{MIM}\right]\left[\mathrm{PF}_{6}\right]$, phosphorous is deficient at the surface while both sulfur and oxygen are enriched, indicating that the [TFSI] anion is dominant over the $\left[\mathrm{PF}_{6}\right]$ anion at the surface. The average composition in the topmost molecular layer was estimated by integrating the depth profiles in the depth region from $0 \mathrm{~nm}$ to $0.8 \mathrm{~nm}$ as was performed in the previous section. The obtained result is also shown in Table 1. A large phosphorous deficiency $(\sim 40 \%)$ and notable enrichment of sulfur and oxygen $(\sim 20 \%)$ are clearly seen indicating surface enrichment of the [TFSI] anion. From the enrichment of sulfur and oxygen, the surface composition is derived to [ $\mathrm{C}_{4} \mathrm{MIM}$ ] $[\mathrm{TFSI}]_{0.6}\left[\mathrm{PF}_{6}\right]_{0.4}$

Figure 6(b) shows the observed leading-edge positions of the constituent elements for $\left[\mathrm{C}_{4} \mathrm{MIM}\right][\mathrm{TFSI}]_{0.5}\left[\mathrm{PF}_{6}\right]_{0.5}$. The leading edge of nitrogen is about $0.15 \mathrm{~nm}$ deeper than that of carbon, indicating that the alkyl chain of the $\left[\mathrm{C}_{4} \mathrm{MIM}\right]$ cation protrudes to the vacuum. Concerning the [TFSI] anion, the leading edges of sulfur and oxygen are located at shallower 
depths than nitrogen by $\sim 0.05 \mathrm{~nm}$ and the fluorine edge is located at a shallower depth than those of sulfur and oxygen by $\sim 0.07 \mathrm{~nm}$. This indicates that the $\mathrm{CF}_{3}$ groups of the [TFSI] anions are pointing toward the vacuum and the $\mathrm{N}\left(\mathrm{SO}_{2}\right)_{2}$ moiety is located shallower than the imidazolium ring by $\sim 0.05 \mathrm{~nm}$. On the other hand, phosphorous edge is located deeper than the nitrogen edge by $\sim 0.14 \mathrm{~nm}$, indicating that $\left[\mathrm{PF}_{6}\right]$ anions are located deeper than the imidazolium ring.

It is noteworthy that the fluorine depth profile has a peak at the surface (Fig. 5(b)) while $\left[\mathrm{C}_{6} \mathrm{MIM}\right][\mathrm{TFSI}]_{0.5}\left[\mathrm{PF}_{6}\right]_{0.5}$ does not show such a surface fluorine peak (Fig. 5(a)). The [TFSI] anion has two stable conformers, cis and trans conformers, and the trans conformer is energetically more stable than the cis conformer. The present result indicates that the fraction of the cis conformer is lager at the surface when the length of alkyl chain of the cation is shorter. The same trend was observed for pure [ $\mathrm{C}_{\mathrm{n}} \mathrm{MIM}$ [TFSI] [34].

Figure 7(b) summarizes the present results: The molecular composition of the topmost molecular layer is $\left[\mathrm{C}_{4} \mathrm{MIM}\right][\mathrm{TFSI}]_{0.6}\left[\mathrm{PF}_{6}\right]_{0.4}$. The alkyl chain of the $\left[\mathrm{C}_{4} \mathrm{MIM}\right]$ cation protrudes to the vacuum. The $\mathrm{CF}_{3}$ groups of the [TFSI] anions are pointing toward the vacuum and the $\mathrm{N}\left(\mathrm{SO}_{2}\right)_{2}$ moiety is located shallower than the imidazolium ring while the $\left[\mathrm{PF}_{6}\right]$ anions are located deeper than the imidazolium ring. These features are almost the same as those observed for $\left[\mathrm{C}_{6} \mathrm{MIM}\right][\mathrm{TFSI}]_{0.5}\left[\mathrm{PF}_{6}\right]_{0.5}$, indicating that the surface structure is essentially independent of the length of the alkyl chain of the $\left[\mathrm{C}_{\mathrm{n}} \mathrm{MIM}\right]$ cation.

\subsection{Equimolar mixture of $\left[\mathrm{C}_{6} \mathrm{MIM}\right]\left[\mathrm{PF}_{6}\right]$ and $\left[\mathrm{C}_{6} \mathrm{MIM}\right][\mathrm{Cl}]$}

Figure 5(c) shows the composition depth profiles of $\left[\mathrm{C}_{6} \mathrm{MIM}\right]\left[\mathrm{PF}_{6}\right]_{0.5}[\mathrm{Cl}]_{0.5}$ derived from the observed HRBS spectrum. The carbon profile has a peak at the surface (at a depth $\sim 0.25 \mathrm{~nm}$ ), indicating the surface enrichment of carbon. All other elements are slightly deficient at the surface region. The average composition of the surface layer of $0.8 \mathrm{~nm}$ thickness was calculated by integrating the profiles and the result is shown in Table 1. The average concentrations of chlorine and phosphorous, which are representatives of two anions, $\left[\mathrm{PF}_{6}\right]$ and $[\mathrm{Cl}]$, respectively, agree with the stoichiometric composition within the experimental error, indicating that there is no surface segregation of the particular anion. 
The leading edge positions of the elements were also derived from the observed profiles and the result was shown in Figure 6(c). The carbon leading edge is located shallower than that of nitrogen by $\sim 0.2 \mathrm{~nm}$, indicating that the alkyl chain of the $\left[\mathrm{C}_{6} \mathrm{MIM}\right]$ cation protrudes to the vacuum. Both fluorine and phosphorous leading edges are located at almost the same depth as nitrogen while the chlorine leading edge is located slightly deeper than nitrogen. This indicates that the $\left[\mathrm{PF}_{6}\right]$ anions are located at almost the same depth as the imidazolium ring while $[\mathrm{Cl}]$ anions are located slightly deeper than the imidazolium ring. The schematic drawing of the determined surface structure is shown in Fig. 7(c).

\subsection{Equimolar mixture of $\left[\mathrm{C}_{6} \mathrm{MIM}\right]$ [TFSI] and $\left[\mathrm{C}_{6} \mathrm{MIM}\right][\mathrm{Cl}]$}

Figure $5(\mathrm{~d})$ shows composition depth profiles of $\left[\mathrm{C}_{6} \mathrm{MIM}\right][\mathrm{TFSI}]_{0.5}[\mathrm{Cl}]_{0.5}$ derived from the observed HRBS spectrum. The average composition of the surface layer of $0.8 \mathrm{~nm}$ thickness was determined by integrating the profiles and the result was shown in Table 1. The determined composition is very close to the stoichiometric composition, indicating that there is no notable enrichment of either $[\mathrm{TFSI}]$ or $[\mathrm{Cl}]$ anions. The leading edge positions of the elements are shown in Fig. 6(d). The nitrogen leading edge is located deeper than the carbon by $\sim 0.2 \mathrm{~nm}$, showing that the alkyl chain of the $\left[\mathrm{C}_{6} \mathrm{MIM}\right]$ cation protrudes to the vacuum. The chlorine edge is located at the same depth as the nitrogen, indicating that $[\mathrm{Cl}]$ anions are located at the same depth as the imidazolium ring. Concerning the [TFSI] anion, the leading edges of sulfur and oxygen are located at shallower depths than nitrogen by $\sim 0.1$ $\mathrm{nm}$ and the fluorine edge is located at a shallower depth than those of the sulfur and oxygen by $\sim 0.08 \mathrm{~nm}$. This indicates that the $\mathrm{CF}_{3}$ groups of the [TFSI] anions are pointing toward the vacuum and the $\mathrm{N}\left(\mathrm{SO}_{2}\right)_{2}$ moiety is located shallower than the imidazolium ring by $\sim 0.1$ nm. There is a large surface peak in the fluorine depth profile (Fig. 5(d)), which indicates the cis conformer is dominant in the surface topmost molecular layer. The schematic drawing of the determined surface structure is shown in Fig. 7(d).

\section{Discussion}

A weak surface segregation of the $[\mathrm{TFSI}]$ anion was observed for $\left[\mathrm{C}_{4} \mathrm{MIM}\right][\mathrm{TFSI}]_{0.5}$ 
$\left[\mathrm{PF}_{6}\right]_{0.5}$ and $\left[\mathrm{C}_{6} \mathrm{MIM}\right][\mathrm{TFSI}]_{0.5}\left[\mathrm{PF}_{6}\right]_{0.5}$. Other IL mixtures studied here show no surface segregation of particular anions. These behaviors might be understood in terms of the surface tension. Table 2 shows the surface tensions $\gamma$ of the ILs used in this study [36, 37]. The surface free energy per ion pair was estimated by $f_{1}=\gamma v^{2 / 3}$ and shown in Table 2, where $v$ is the volume of one ion pair. Although the surface tension varies over a wide range, the obtained surface free energies per ion pair are almost the same. The ratio of the anions at the surface of IL mixture was estimated using the Boltzmann factor. The estimated ratios are shown in Table 3 together with the present observation. The estimated ratios are roughly in agreement with the observed results within $+-10 \%$. There is, however, general tendency that larger anions have larger fractions than the estimated ones. This seems reasonable, because larger molecules are generally more polarizable. When more polarizable molecules occupy the surface, the electric field is easily screened and does not extend outside. This reduces the surface energy and stabilizes the surface.

The present result is very different from the recent TOF-SIMS measurement, which showed very strong surface segregation of larger molecules [27]. For example, the [TFSI] anion is enriched at the surface of $\left[\mathrm{C}_{4} \mathrm{MIM}\right][\mathrm{TFSI}]_{0.5}\left[\mathrm{PF}_{6}\right]_{0.5}$ with coverage of $\sim 99 \%$, while our result shows only $60 \%$. Similar discrepancies were also observed between TOF-SIMS and XPS results. The TOF-SIMS measurement showed that surface enrichment of the $\left[\mathrm{C}_{8} \mathrm{MIM}\right]$ cation with coverage of $\sim 95 \%$ in $\left[\mathrm{C}_{8} \mathrm{MIM}\right]_{0.5}\left[\mathrm{C}_{2} \mathrm{MIM}\right]_{0.5}\left[\mathrm{BF}_{4}\right]$ while XPS measurements showed no surface enrichment of the $\left[\mathrm{C}_{12} \mathrm{MIM}\right]$ cation in $\left[\mathrm{C}_{12} \mathrm{MIM}\right]_{0.5}\left[\mathrm{C}_{2} \mathrm{MIM}\right]_{0.5}[\mathrm{TFSI}]$ [24]. Our previous study also showed no surface enrichment of $\left[\mathrm{C}_{6} \mathrm{MIM}\right]$ cation in $\left[\mathrm{C}_{6} \mathrm{MIM}\right]_{0.5}\left[\mathrm{C}_{2} \mathrm{MIM}\right]_{0.5}[\mathrm{TFSI}]$ [34]. The result of TOF-SIMS indicates that larger molecules tend to segregate to the surface. It should be noted that the TOF-SIMS analysis relies on the assumption that the yield of the secondary ion is proportional to the surface concentration of the relevant molecule. The present result indicates that larger anions have tendency to occupy shallower depths than the smaller anions. Because the secondary ions produced at deeper depths have larger neutralization probabilities due to its longer path length inside the target. This results in underestimate of the concentration of these molecules. This could be the origin of the discrepancy between TOF-SIMS and other 
surface analysis techniques.

\section{Conclusion}

The surface structures of $\left[\mathrm{C}_{4} \mathrm{MIM}\right][\mathrm{TFSI}],\left[\mathrm{C}_{4} \mathrm{MIM}\right]\left[\mathrm{PF}_{6}\right],\left[\mathrm{C}_{6} \mathrm{MIM}\right][\mathrm{TFSI}],\left[\mathrm{C}_{6} \mathrm{MIM}\right]$ $\left[\mathrm{PF}_{6}\right]$ and $\left[\mathrm{C}_{6} \mathrm{MIM}\right][\mathrm{Cl}]$ and the equimolar mixtures of these ILs having a common cation, i.e. $\left[\mathrm{C}_{4} \mathrm{MIM}\right] \quad[\mathrm{TFSI}]_{0.5}\left[\mathrm{PF}_{6}\right]_{0.5}, \quad\left[\mathrm{C}_{6} \mathrm{MIM}\right] \quad[\mathrm{TFSI}]_{0.5}\left[\mathrm{PF}_{6}\right]_{0.5}, \quad\left[\mathrm{C}_{6} \mathrm{MIM}\right] \quad[\mathrm{TFSI}]_{0.5}[\mathrm{Cl}]_{0.5}$ and $\left[\mathrm{C}_{6} \mathrm{MIM}\right]\left[\mathrm{PF}_{6}\right]_{0.5}[\mathrm{Cl}]_{0.5}$ were observed by HRBS. For pure ILs, the alkyl chains of the cations protrude to the vacuum and the anions are located at almost the same depth as the imidazolium rings of the cations. The [TFSI] anion also shows a preferential orientation at the surface with $\mathrm{CF}_{3}$ groups pointing toward the vacuum. For the mixtures, the molecules have the same preferential orientations at the surface as in the pure ILs. There is a tendency that larger anions are located at shallower depths than smaller anions in the mixture. In addition, the $[\mathrm{TFSI}]$ anion is found to be slightly enriched at the surface relative to $\left[\mathrm{PF}_{6}\right]$ with coverage of $60 \%$ for $\left[\mathrm{C}_{4(6)} \mathrm{MIM}\right][\mathrm{TFSI}]_{0.5}\left[\mathrm{PF}_{6}\right]_{0.5}$ although no surface segregation is observed for other mixtures. These results can be roughly explained in terms of the surface tension.

\section{References}

[1] P. Wasserscheid, and W. Keim, Angew. Chem. Int. Ed. 39 (2000) 3772.

[2] R. Sheldon, Chem. Commun. 23 (2001) 2399.

[3] J. Dupont, R. F. Souza, and P. A. Suarez, Chem. Rev. 102 (2002) 3667.

[4] Yu-Feng Lin, and I. Wen Sun, Electron. Acta, 45 (2000) 3163.

[5] F. Endres, Chem. Phys. Chem., 3 (2002) 144.

[6] W. Freyland, C. A. Zell, S. Abedin, El Zein, and F. Endres, Electron. Acta, 48 (2003) 3053.

[7] B. Garcia, S. Lavalle'e, G. Perron, C. Michot, and M. Armand, Electrochim. Acta, 49 (2004) 4583.

[8] H. Matsumoto, H. Sakaebe, and K. Tatsumi, J. Power Sources, 146 (2005) 45.

[9] M. Ue, M. Takeda, A. Toriumi, A. Kominato, R. Hagiwara, and Y. Ito, J. Electrochem. Soc., 150 (2003) A499.

[10] Y. Kim, Y. Matsuzawa, S. Ozaki, K. C. Park, C. Kim, M. Endo, H. Yoshida, G. Masuda, T. 
Sato, and M. S. Dresselhaus, J. Electrochem. Soc., 152 (2005) A710.

[11] A. Noda, A. Susan, K. Kudo, S. Mitsushima, K. Hayamizu, and M. Watanabe, J. Phys. Chem. B, 107 (2003) 4024.

[12] R. Hagiwara, T. Nohira, K. Matsumoto, and Y. Tamba, Electrochem. Solid-State Lett., 8 (2005) A231.

[13] C. Ye, W. Liy, Y. Chen, and L. Yu, Chemical Communications 2001 (2001) 2244.

[14] T. J. Gannon, G. Law, and P. R. Watson, Langmuir, 15 (1999) 8429.

[15] G. Law, P. R. Watson, A. J. Carmichael, and K. R. Seddon, Phys. Chem. Chem. Phys., 3 (2001) 2879.

[16] S. Baldelli, J. Phys. Chem. B, 107 (2003) 6148.

[17] S. Rivera-Rubero and S. Baldelli, J. Am. Chem. Soc., 126 (2004) 11788.

[18] T. imori, T. Iwahashi, H. Ishii, K. Seki, Y. Ouchi, R. Osawa, H. Hamaguchi, and D. Kim, Chem. Phys. Lett., 389 (2004) 321.

[19] T. Iimori, T. Iwahashi, K. Kanai, K. Seki, J. Sung, D. Kim, H. Hamaguchi, and Y. Ouchi, J. Phys. Chem. B, 111 (2007) 4860.

[20] E. Sloutskin, B. M. Ocko, L. Tamam, I. Kuzmenko, T. Gog, and M. Deutsch, J. Am. Chem. Soc., 127 (2005) 7796.

[21] V. Lockett, R. Sedev, C. Bassel, and J. Ralston, Phys. Chem. Chem. Phys., 10 (2008) 1330.

[22] K. R. J. Lovelock, C. Kolbeck, T. Cremer, N. Paape, P. S. Schulz, P. Wasserscheid, F. Maier, and H. P. Steinrück, J. Phys. Chem. B 113 (2009) 2854.

[23] C. Kolbeck, T. Cremer, K. R. J. Lovelock, N. Paape, P. S. Schulz, P. Wasserscheid, F.

Maier, and H.-P. Steinrück, J. Phys. Chem. B 113 (2009) 8682.

[24] F. Maier, T. Cremer, C. Kolbeck, K. R. J. Lovelock, N. Paape, P. S. Schulz, P.

Wasserscheid, and H.-P. Steinrück, Phys. Chem. Chem. Phys. 12 (2010) 1905.

[25] S. Caporali, U. Bardi, and A. Lavacchi, J. Elec. Spec. and Rel. Phenomena, 151 (2006) 4.

[26] O. Höfft, S. Bahr, M. Himmerlich, S. Krischok, J. A. Schaefer, and V. Kempter, Langumuir 22 (2006) 7120.

[27] J. Günster, O. Höfft, S. Krischok, R. Souda, Surf. Sci. 602 (2008) 3403. 
[28] R. Souda, Surf. Sci. 604 (2010) 1694.

[29] K. Nakajima, A. Ohno, M. Suzuki, and K. Kimura, Langmuir 24 (2008) 4482.

[30] H. Hashimoto, A. Ohno, K. Nakajima, M. Suzuki, H. Tsuji, and K. Kimura, Surf. Sci. 604 (2010) 464.

[31] A. Ohno, H. Hashimoto, K. Nakajima, M. Suzuki, and K. Kimura, J. Chem. Phys. 130 (2009) 204705.

[32] K. Nakajima, A. Ohno, H. Hashimoto, M. Suzuki, and K. Kimura, J. Chem. Phys. 133 (2010) 044702.

[33] C. Ridings, V. Lockett, and G. Andersson, Phys. Chem. Chem. Phys. 13 (2011) 17177.

[34] K. Kimura, S. Joumori, Y. Oota, K. Nakajima, and M. Suzuki, Nucl. Instr. and Methods B, 219-220 (2004) 351.

[35] M. E. Saeckers, S. T. Govoni, D. V. Kowalski, M. E. King, and G. M. Nathanson, Science 252 (1991) 1421.

[36] M.H. Ghatee, A.R. Zolghadr, Fluid Phase Equilibria, 263 (2008) 168.

[37] R. Osada, T. Hoshino, K. Okada, Y. Ohmasa, and M. Yao, J. Chem. Phys. 130 (2009) 184705 .

\section{Figure captions}

Fig. 1 HRBS spectrum of $\left[\mathrm{C}_{6} \mathrm{MIM}\right]\left[\mathrm{PF}_{6}\right]$ observed at a scattering angle $\theta=50.6^{\circ}$. The incident energy is $400 \mathrm{keV}$ and the incident angle is $42.4^{\circ}$. The arrows show the leading edges of constituent elements in the observed spectrum. The solid lines show the simulated spectrum for stoichiometric composition. The agreement between the observed and calculated spectra is reasonably good except for small deviations seen around the leading edges of the elements.

Fig. 2 Composition depth profiles for $\left[\mathrm{C}_{6} \mathrm{MIM}\right]\left[\mathrm{PF}_{6}\right]$ derived from the observed HRBS spectrum. The horizontal dashed lines show the stoichiometric composition. Typical errors are also shown. The carbon profile has a peak at a depth $d \sim 0.3 \mathrm{~nm}$, while deficiency of fluorine and phosphorous is seen in the surface region $d<0.4 \mathrm{~nm}$, suggesting that the $\left[\mathrm{PF}_{6}\right]$ 
anion is located slightly deeper region than the alkyl chain of the cation.

Fig. 3 Leading edge positions of the constituent elements for (a) $\left[\mathrm{C}_{6} \mathrm{MIM}\right]\left[\mathrm{PF}_{6}\right]$, (b) $\left[\mathrm{C}_{6} \mathrm{MIM}\right][\mathrm{TFSI}],(\mathrm{c})\left[\mathrm{C}_{6} \mathrm{MIM}\right] \mathrm{Cl},(\mathrm{d})\left[\mathrm{C}_{4} \mathrm{MIM}\right][\mathrm{TFSI}]$ and (e) $\left[\mathrm{C}_{4} \mathrm{MIM}\right]\left[\mathrm{PF}_{6}\right]$.

Fig. 4 HRBS spectrum of equimolar mixture of $\left[\mathrm{C}_{6} \mathrm{MIM}\right][\mathrm{TFSI}]$ and $\left[\mathrm{C}_{6} \mathrm{MIM}\right]\left[\mathrm{PF}_{6}\right]$ observed at a scattering angle $\theta=50.7^{\circ}$. The incident energy was $400 \mathrm{keV}$ and the incident angle $42.3^{\circ}$. For comparison, the simulated spectrum for stoichiometric composition is also shown by a solid line. The agreement is roughly good except for small deviations seen around the leading edges of the elements.

Fig. 5 Composition depth profiles derived from the observed HRBS spectra for (a) $\left[\mathrm{C}_{6} \mathrm{MIM}\right][\mathrm{TFSI}]_{0.5}\left[\mathrm{PF}_{6}\right]_{0.5}$, (b) $\left[\mathrm{C}_{4} \mathrm{MIM}\right][\mathrm{TFSI}]_{0.5}\left[\mathrm{PF}_{6}\right]_{0.5}$ (c) $\left[\mathrm{C}_{6} \mathrm{MIM}\right][\mathrm{TFSI}]_{0.5}[\mathrm{Cl}]_{0.5}$, (d) $\left[\mathrm{C}_{6} \mathrm{MIM}\right]\left[\mathrm{PF}_{6}\right]_{0.5}[\mathrm{Cl}]_{0.5}$. The horizontal dashed lines show the stoichiometric composition. Thypical errors are also shown.

Fig. 6 Leading edge positions of the constituent elements for (a) $\left[\mathrm{C}_{6} \mathrm{MIM}\right][\mathrm{TFSI}]_{0.5}\left[\mathrm{PF}_{6}\right]_{0.5}$, (b) $\left[\mathrm{C}_{4} \mathrm{MIM}\right][\mathrm{TFSI}]_{0.5}\left[\mathrm{PF}_{6}\right]_{0.5}$ (c) $\left[\mathrm{C}_{6} \mathrm{MIM}\right][\mathrm{TFSI}]_{0.5}[\mathrm{Cl}]_{0.5}$, (d) $\left[\mathrm{C}_{6} \mathrm{MIM}\right]\left[\mathrm{PF}_{6}\right]_{0.5}[\mathrm{Cl}]_{0.5}$.

Fig. 7 Schematic drawings of the surface structures of (a) $\left[\mathrm{C}_{6} \mathrm{MIM}\right][\mathrm{TFSI}]_{0.5}\left[\mathrm{PF}_{6}\right]_{0.5}$, (b) $\left[\mathrm{C}_{4} \mathrm{MIM}\right][\mathrm{TFSI}]_{0.5}\left[\mathrm{PF}_{6}\right]_{0.5}$. (c) $\left[\mathrm{C}_{6} \mathrm{MIM}\right][\mathrm{TFSI}]_{0.5}[\mathrm{Cl}]_{0.5}$, (d) $\left[\mathrm{C}_{6} \mathrm{MIM}\right]\left[\mathrm{PF}_{6}\right]_{0.5}[\mathrm{Cl}]_{0.5}$. 
Table 1 Experimentally determined surface compositions for equimoler mixtures of ILs. The stoichiometric compositions are shown in parentheses.

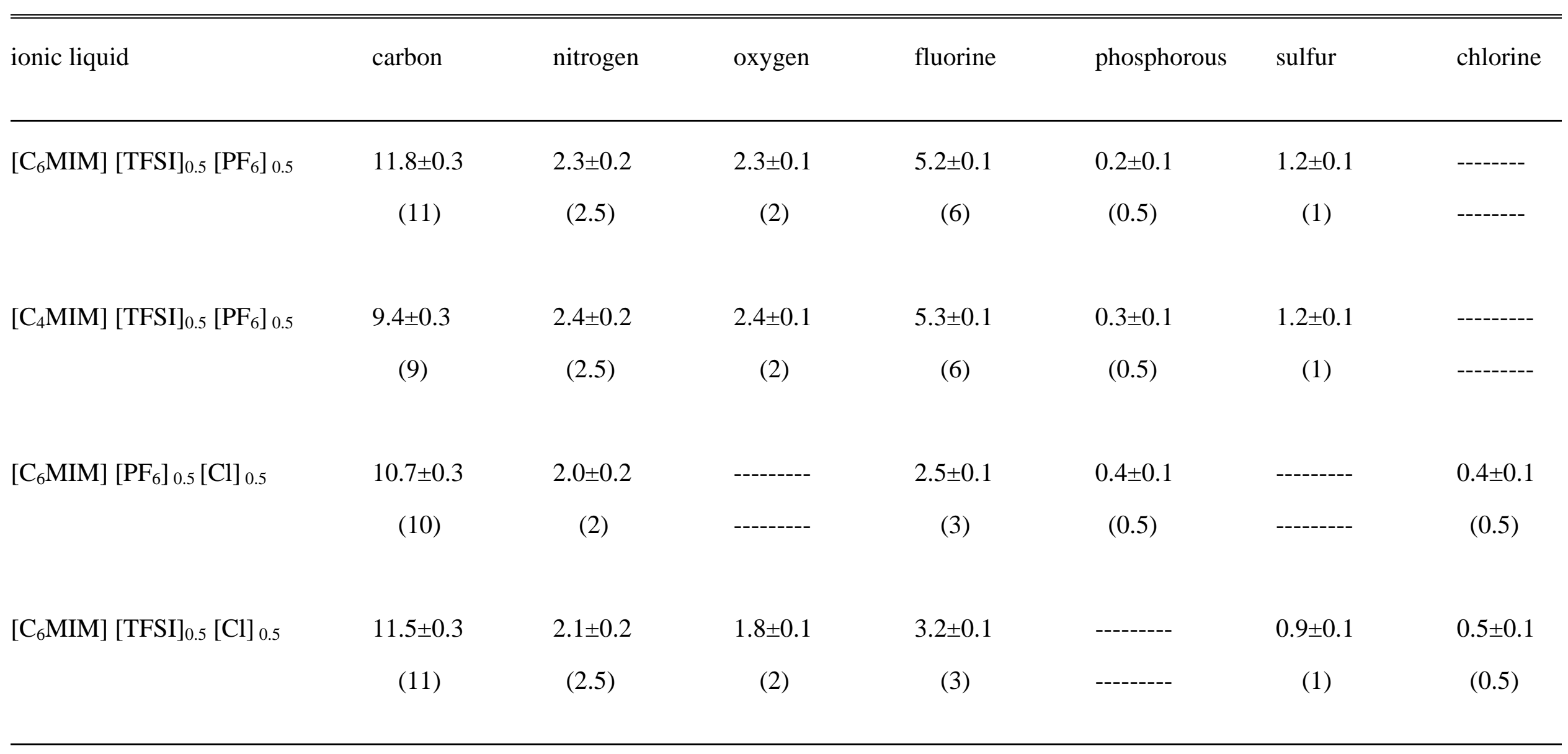


Table 2 Surface tension $[36,37]$ and estimated surface free energy per ion pair.

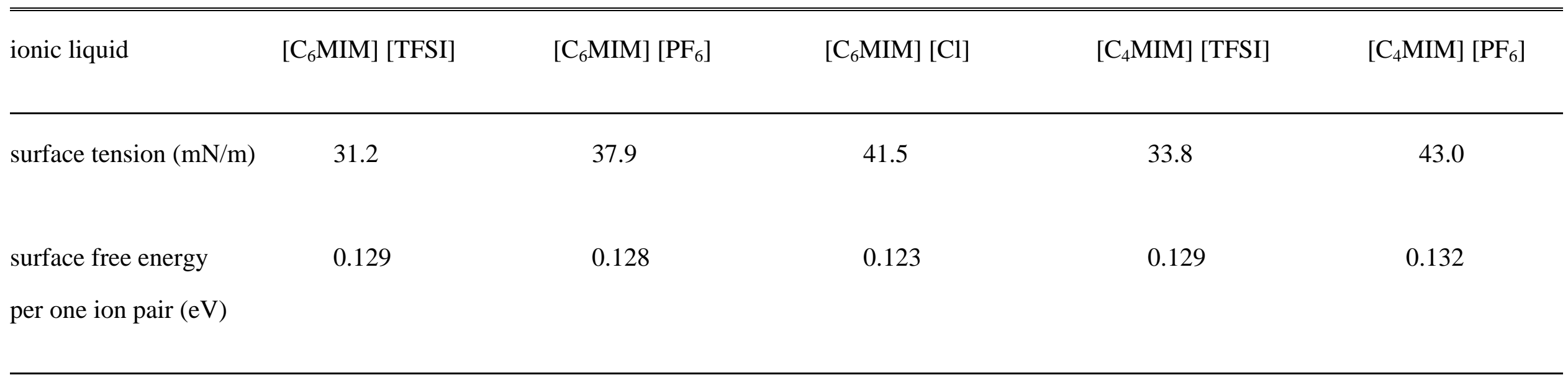


Table 3 Composition ratio of anions at the surface estimated from the surface free energy. The observed results are also shown for comparison.

\begin{tabular}{lll} 
Mixture of ionic liquids & estimated ratio & observed ratio \\
\hline$\left[\mathrm{C}_{6} \mathrm{MIM}\right][\mathrm{TFSI}]_{0.5}\left[\mathrm{PF}_{6}\right]_{0.5}$ & {$[\mathrm{TFSI}]:\left[\mathrm{PF}_{6}\right]=49: 51$} & {$[\mathrm{TFSI}]:\left[\mathrm{PF}_{6}\right]=6: 4$} \\
{$\left[\mathrm{C}_{4} \mathrm{MIM}\right][\mathrm{TFSI}]_{0.5}\left[\mathrm{PF}_{6}\right]_{0.5}$} & {$[\mathrm{TFSI}]:\left[\mathrm{PF}_{6}\right]=53: 47$} & {$[\mathrm{TFSI}]:[\mathrm{PF} 6]=6: 4$} \\
{$\left[\mathrm{C}_{6} \mathrm{MIM}\right][\mathrm{PF}]_{0.5}[\mathrm{Cl}]_{0.5}$} & {$[\mathrm{PF} 6]:[\mathrm{Cl}]=45: 55$} & {$[\mathrm{PF} 6]:[\mathrm{Cl}]=5: 5$} \\
{$\left[\mathrm{C}_{6} \mathrm{MIM}\right][\mathrm{TFSI}]_{0.5}[\mathrm{Cl}]_{0.5}$} & {$[\mathrm{TFSI}]:[\mathrm{Cl}]=44: 56$} & {$[\mathrm{TFSI}]:[\mathrm{Cl}]=5: 5$}
\end{tabular}




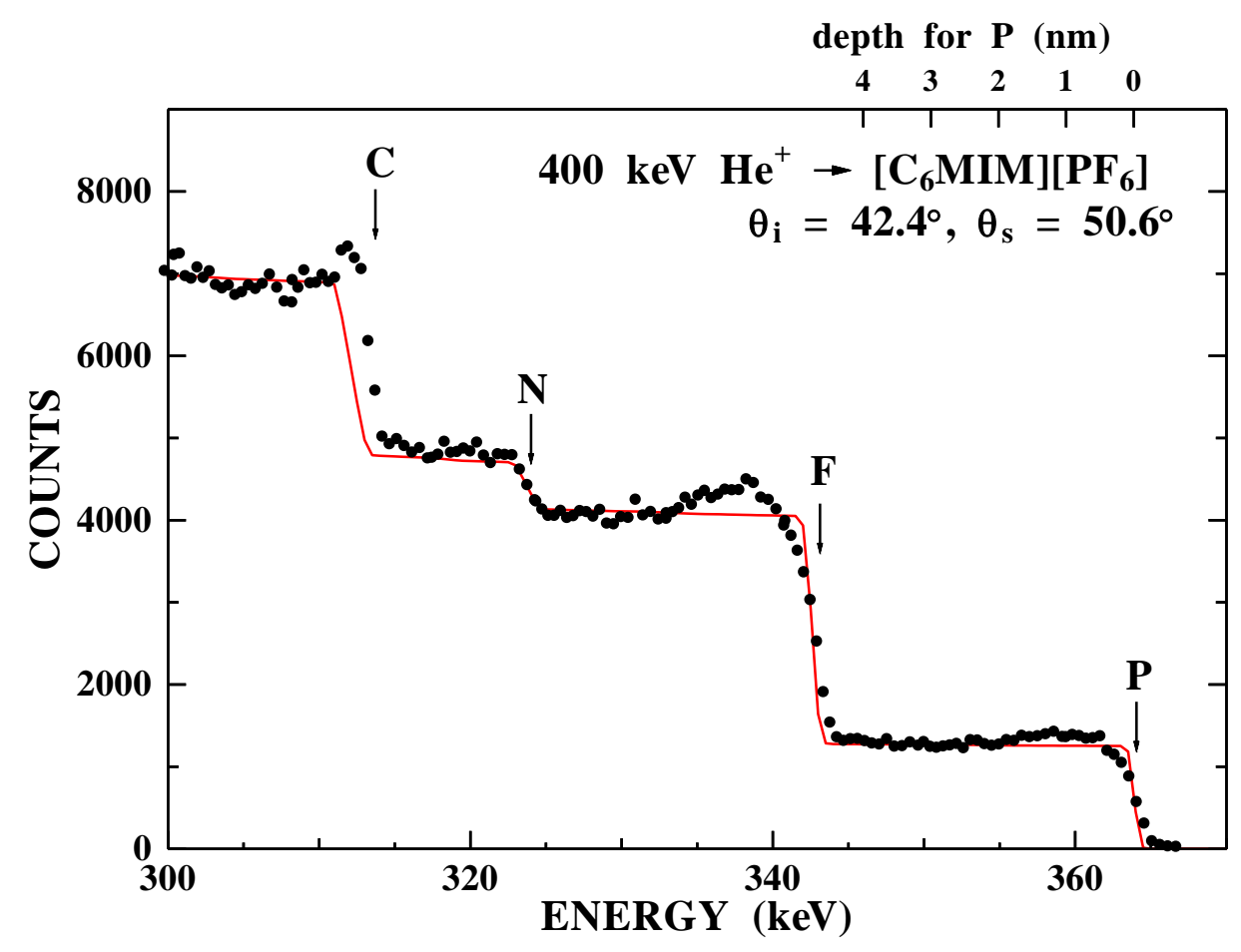

Fig. 1

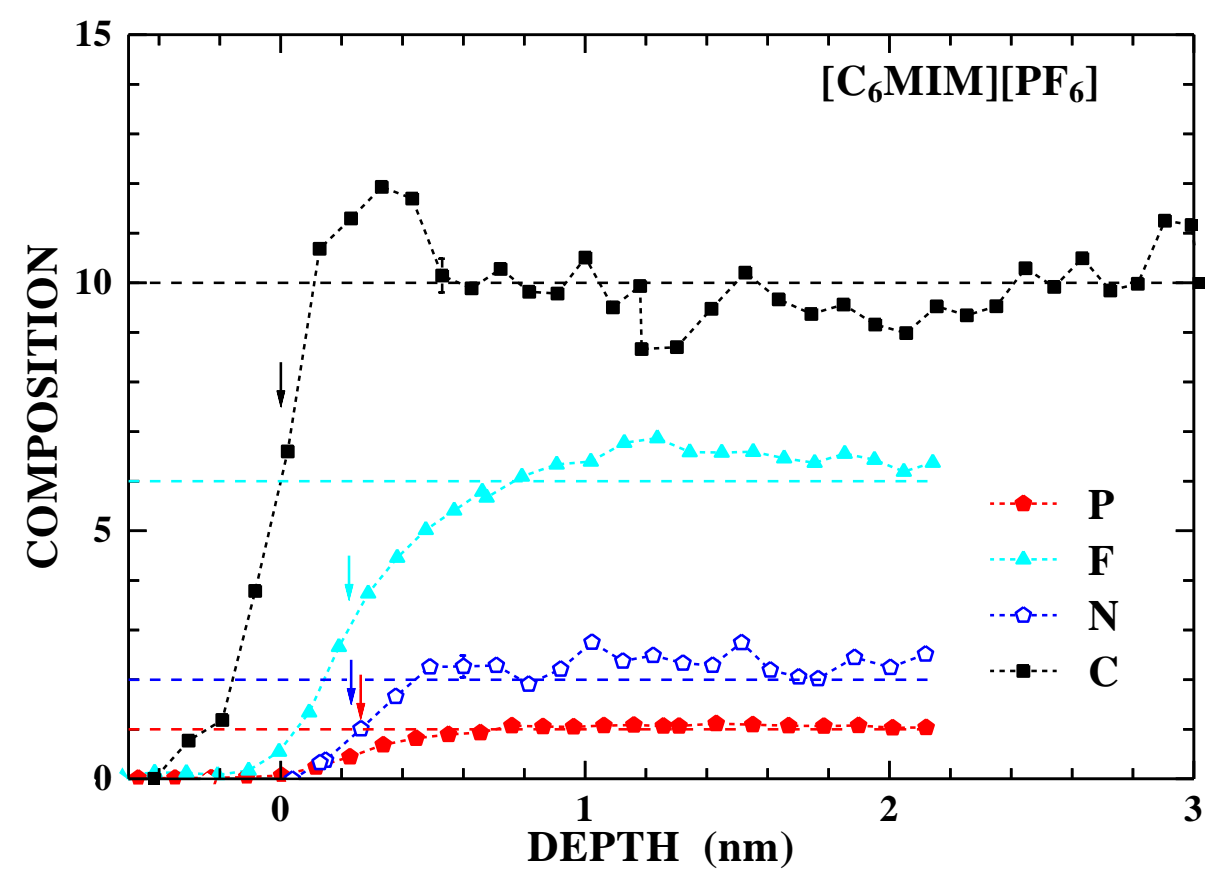

Fig. 2 


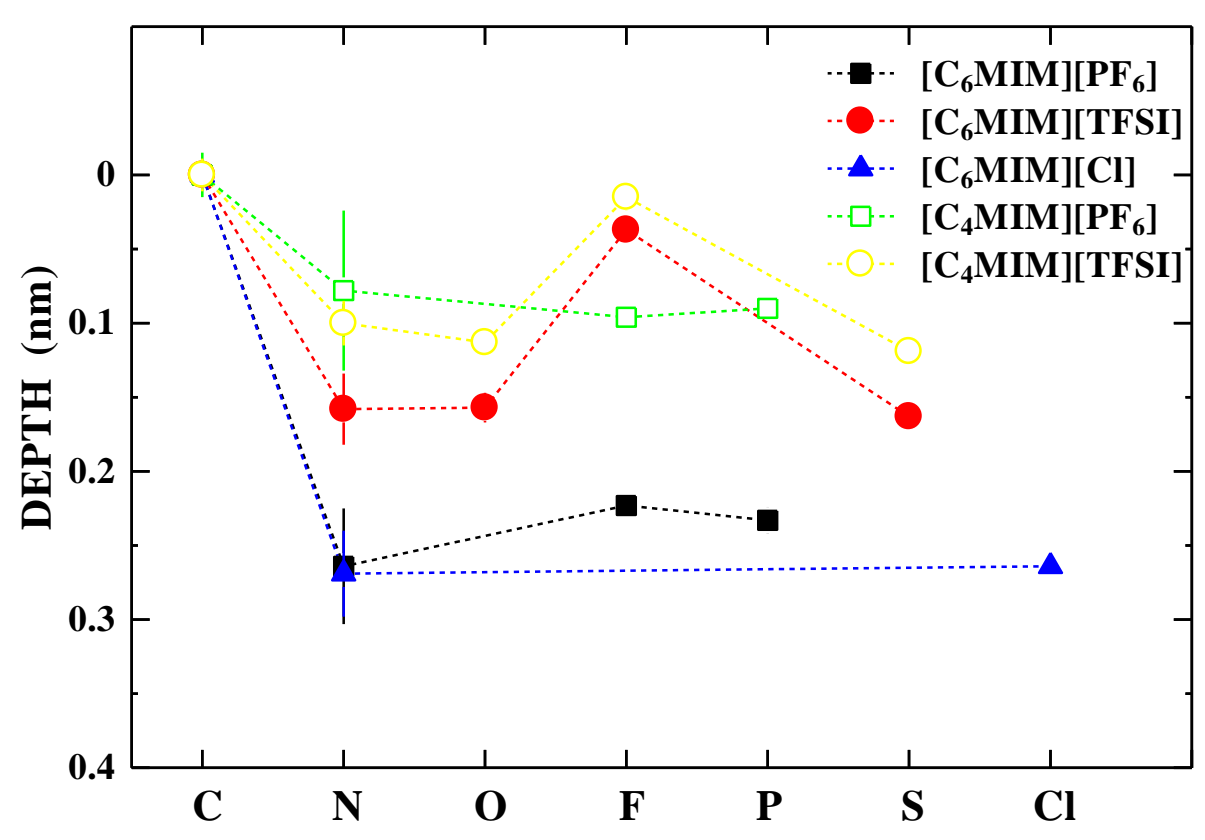

Fig. 3

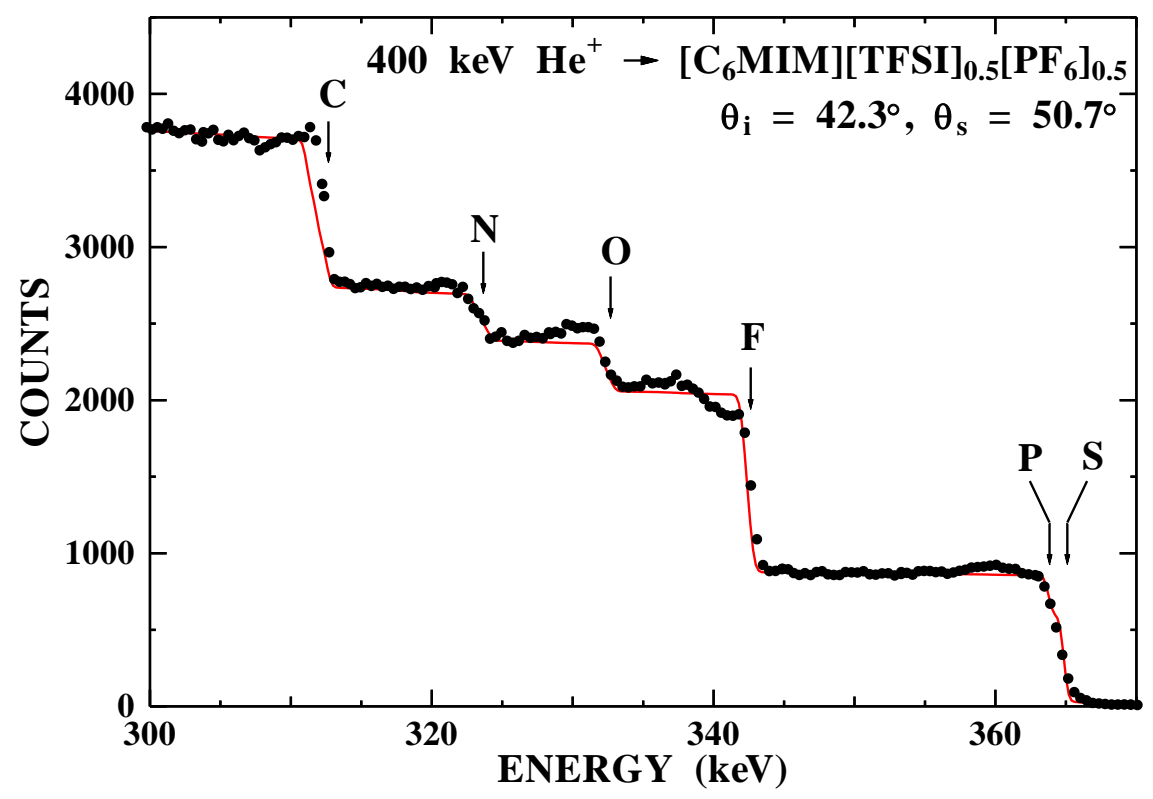

Fig. 4 


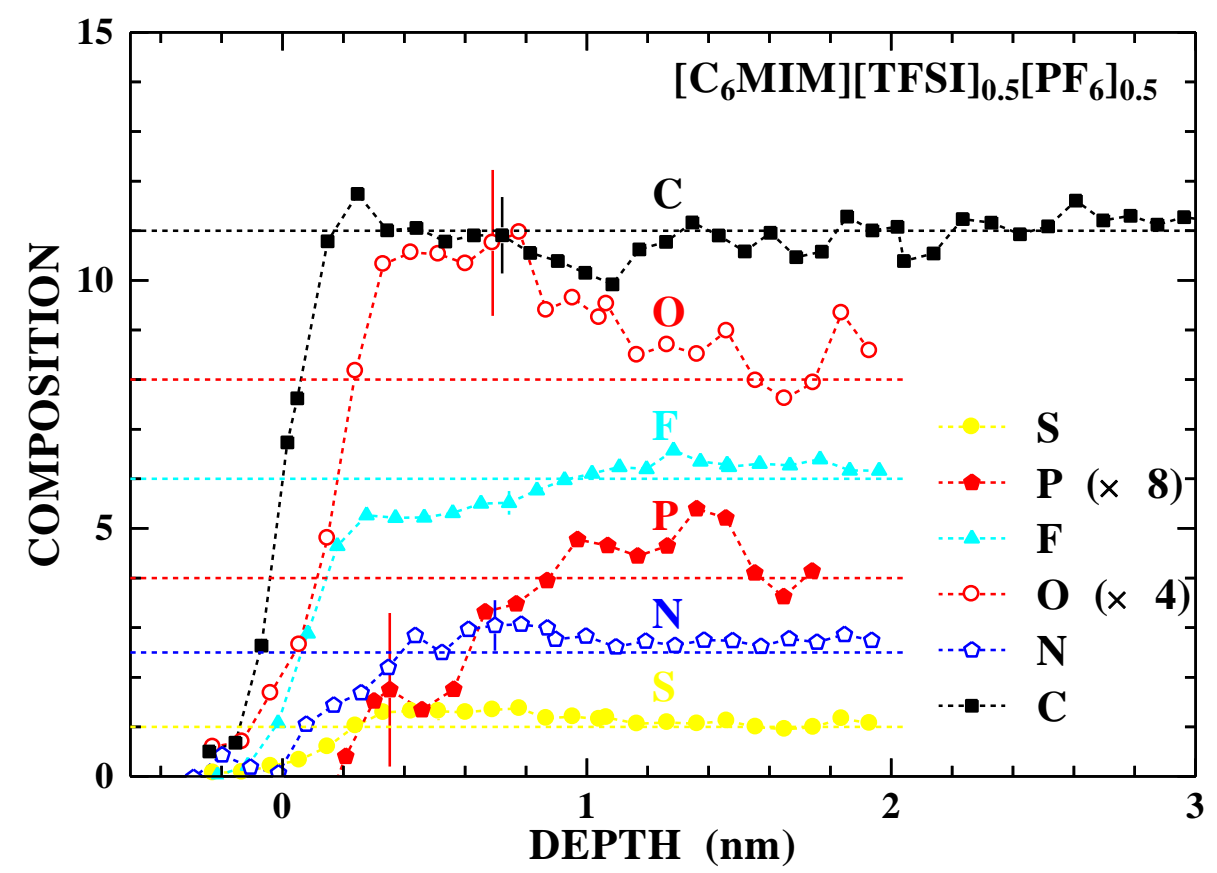

Fig. 5(a)

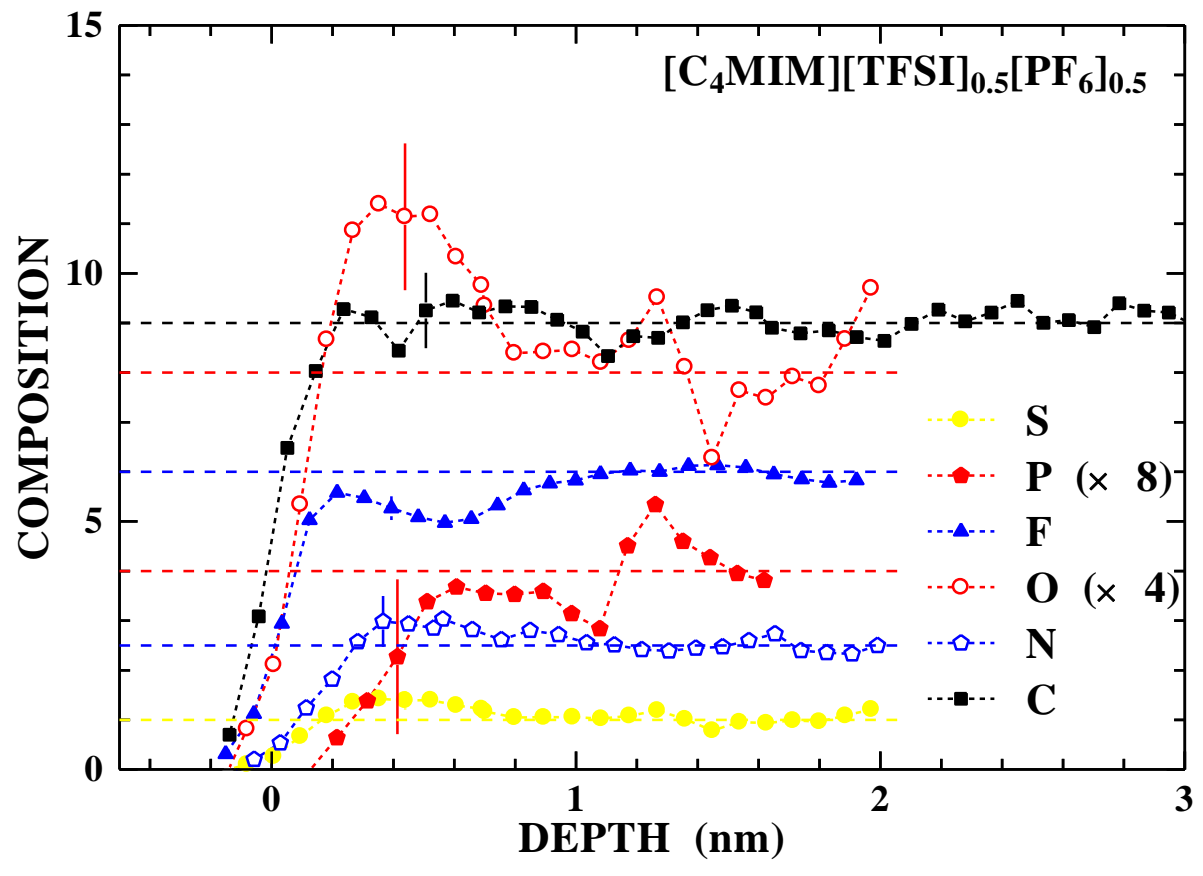

Fig. 5(b) 


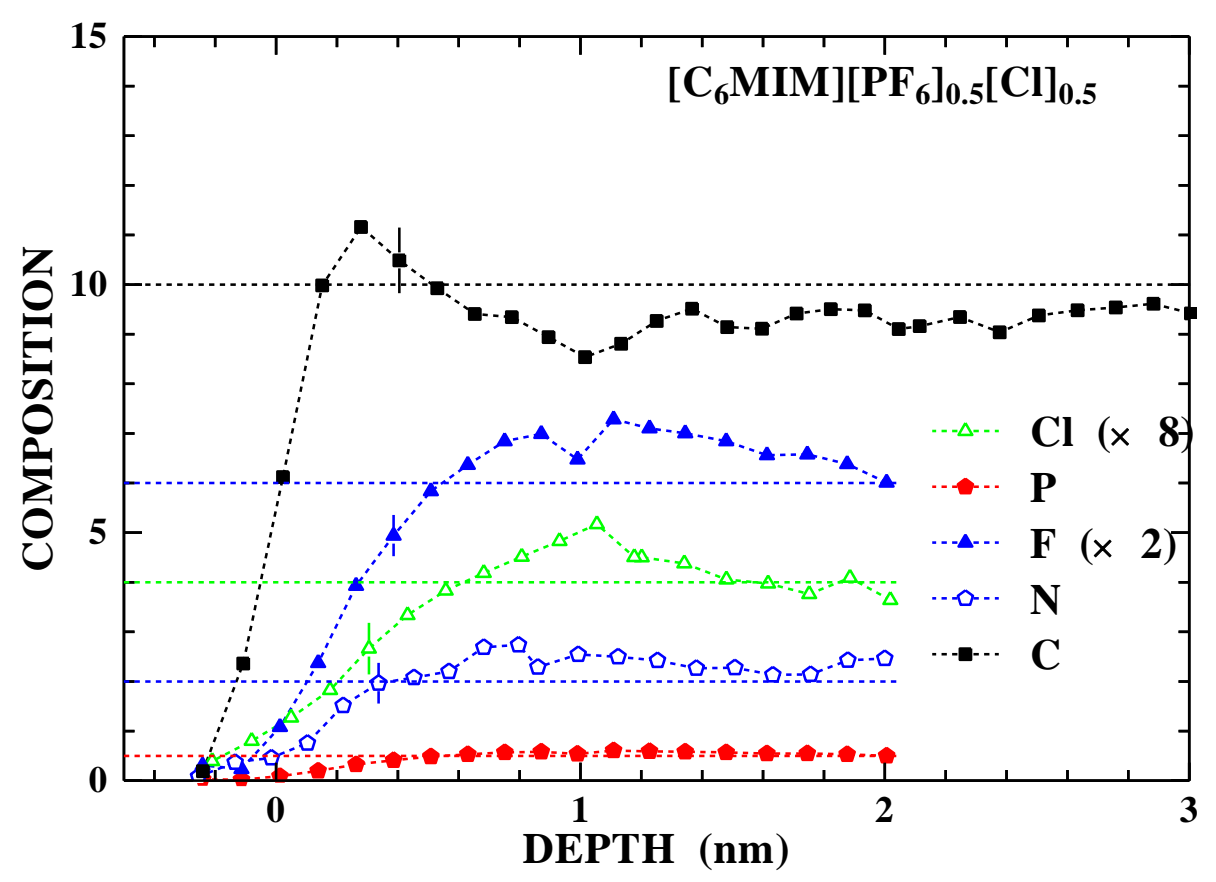

Fig. 5(c)

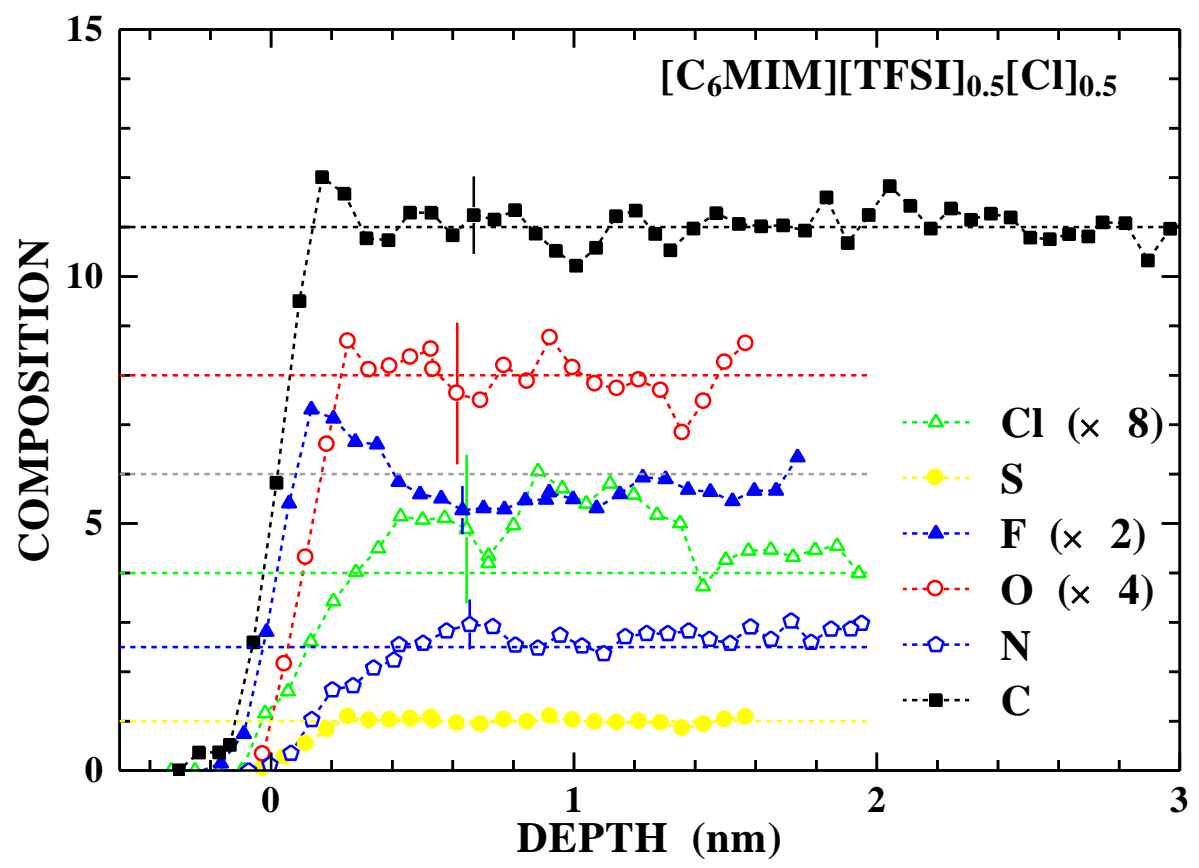

Fig. 5(d) 


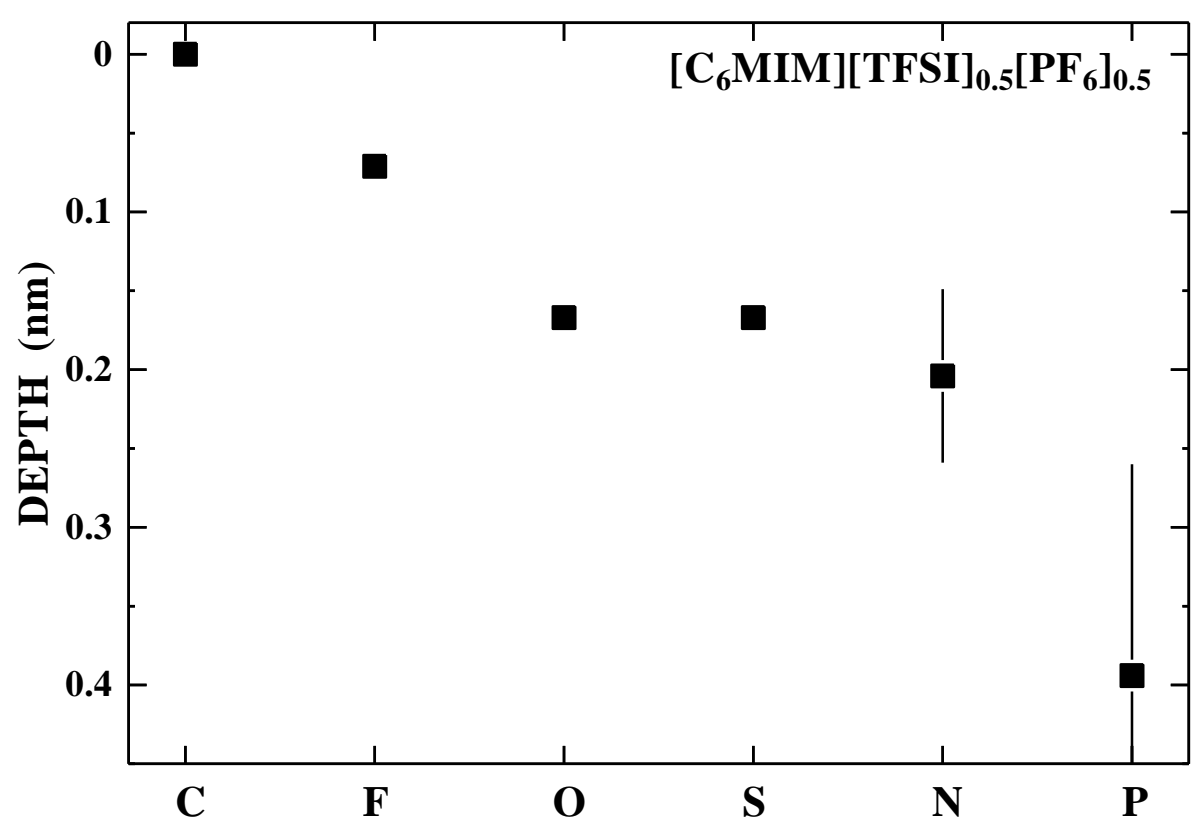

Fig. 6(a)

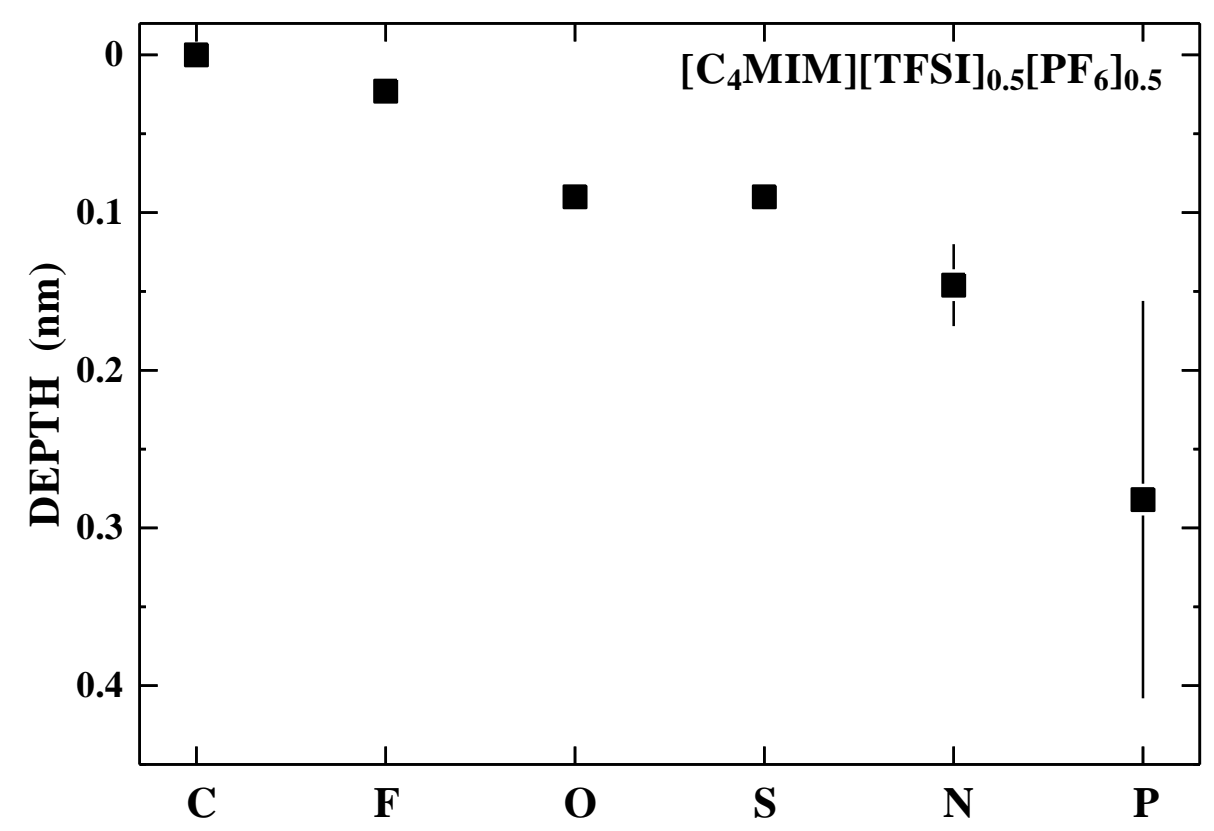

Fig. 6(b) 


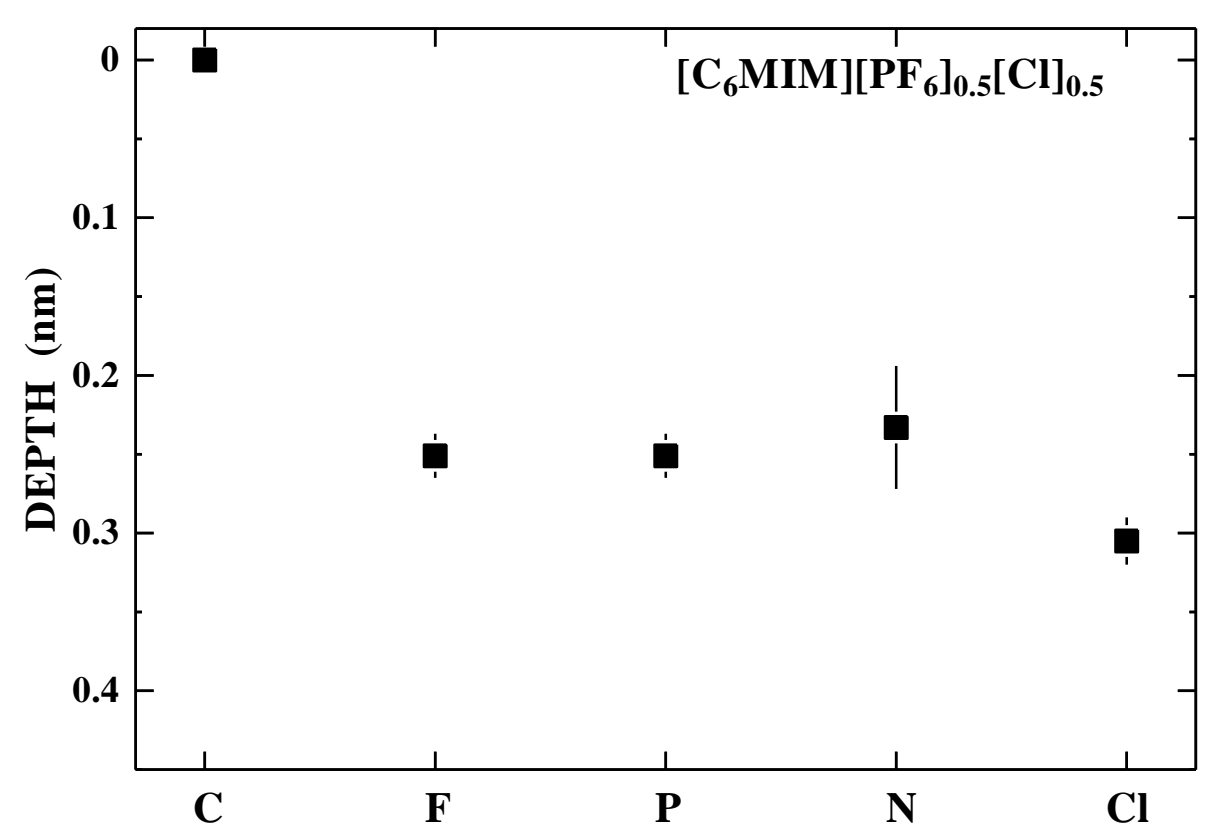

Fig. 6(c)

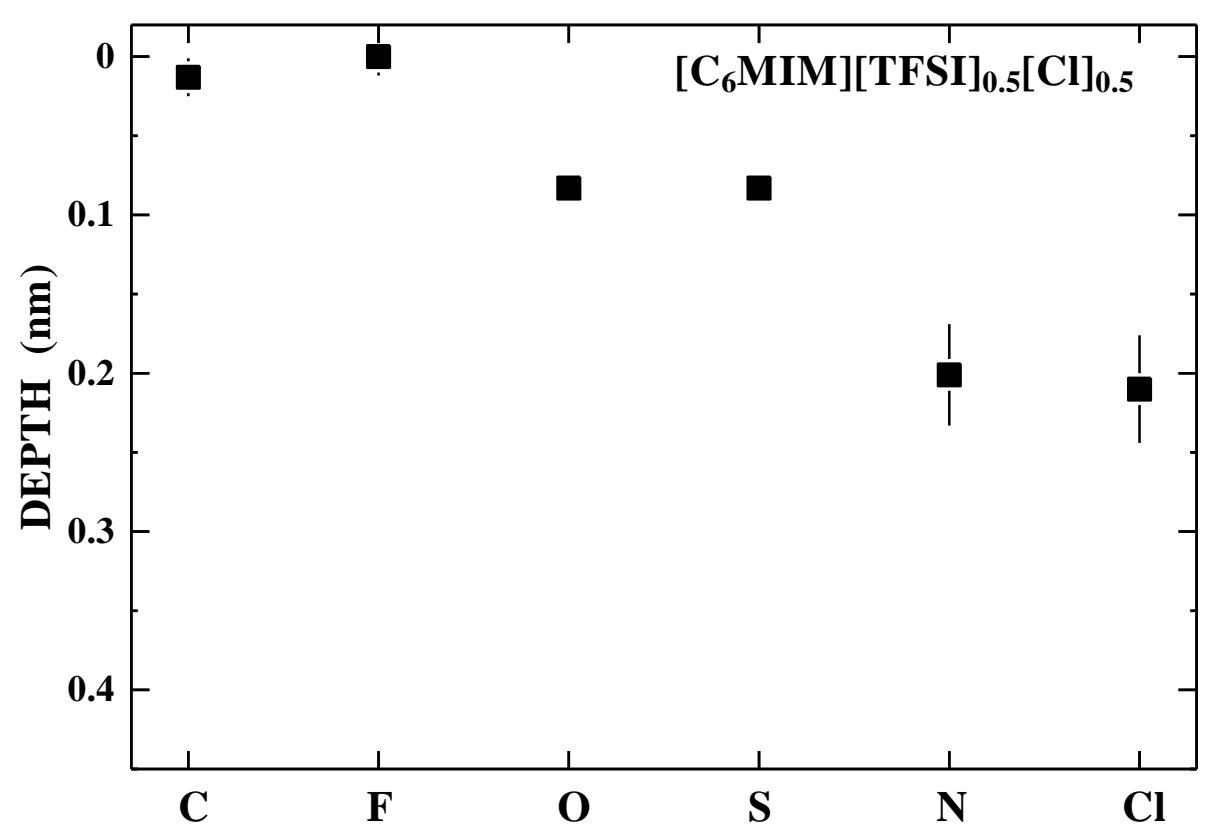

Fig. 6(d) 
$\left[\mathrm{C}_{6} \mathrm{MIM}\right]\left[\mathrm{TFSI}_{0.5}\left[\mathrm{PF}_{6}\right]_{0.5}\right.$

Fig. 7(a)

$\left[\mathrm{C}_{4} \mathrm{MIM}\right][\mathrm{TFSI}]_{0.5}\left[\mathrm{PF}_{6}\right]_{0.5}$

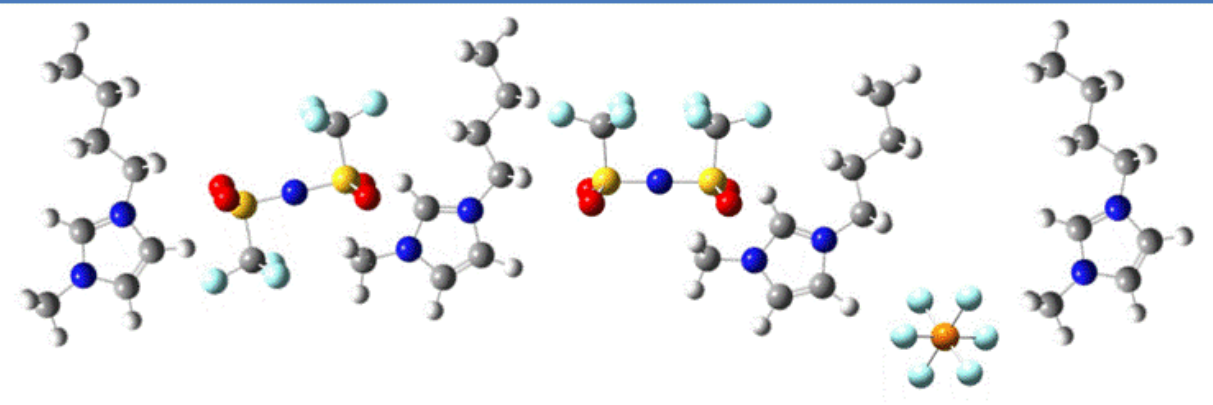

Fig. 7(b) 
$\left[\mathrm{C}_{6} \mathrm{MIM}\right]\left[\mathrm{PF}_{6}\right]_{0.5}[\mathrm{Cl}]_{0.5}$

Fig. 7(c)

$\left[\mathrm{C}_{6} \mathrm{MIM}\right][\mathrm{TFSI}]_{0.5}[\mathrm{Cl}]_{0.5}$

Fig. 7(d) 